\section{Response to report on the CITES conference in Nairobi, insofar as it refers to whales}

Sharp (2000) writes that '...the IWC IInternational Whaling Committee] has been advised by its Scientific Committee that minke whale populations have recovered, but has declined to adopt the necessary management system to regulate any agreed trade.' The first part of this statement is simply untrue and the second part is a distortion of the actual situation.

As to the second part, the IWC, far from 'declining' to act, is quite vigorously working on a management system, having agreed to the scientific part but still facing difficulties with the essential international inspection and enforcement elements - not least because of foot-dragging by whaling countries. Promises from whaling nations that any future exploitation of whales will be sustainable, should be taken with a pinch of salt and are a very different matter from adopting effective measures that ensure that such an aim is met in practice. More generally, the history of the exploitation of wildlife demonstrates that claims of sustainability are rarely met (Papastavrou, 1998).

As to the stock 'recovery' matter, we would challenge Sharp to provide reference for his claim. The Scientific Committee's advice has been until now quite the contrary. Repeated sighting surveys over many years, especially in the Antarctic, have not revealed any clear trend, up or down. This is not because there is no trend but because the precision of even the best surveys is not adequate for detecting trends except perhaps over many decades. No one has predicted any recovery because the Southern Hemisphere minke stocks have never claimed to have been depleted! But these whales do in any case feed in an internationally protected area, called by the IWC as the Southern Ocean Whale Sanctuary.

Interestingly, the Scientific Committee at the recent IWC meeting in Adelaide, expressed a concensus opinion that the results of the latest surveys - the data from which have yet to be fully analysed - suggested that the minke numbers were 'appreciably less' than given by earlier surveys, and that the Committee is unable to give any estimate of current numbers. This does not mean that they have actually declined - we shall learn that, perhaps next year when full analyses have been completed - but it certainly does not support any claim of 'recovery'.
Elsewhere, the status of minke whales is very different. Both this year and the last, the IWC Scientific Committee expressed concern about the state of the minke whales between Korea and Japan, known as the J-stock'. This population is threatened not only by Japan's continued 'scientific' whaling but also because of a high level of catches in fishing nets. Some analyses suggest that at the present rate of catching, it is heading towards extinction.

Thus, the situation is complicated by the differing status of the various populations of minke whales. In addition, there is the acceptance by the scientific community that there are at least two, possibly three species of minke whale, as well as several biologically distinct populations of each. So Sharp's assertion of recovery is, to say the least, uninformed.

Sharp also asserts that the Norwegian proposal for downlisting minke whales was more winningly argued than the Japanese one, and that 'the Norwegians had a better case'. We make no stylistic judgements but in the substance, the truth is the contrary, at least so far as application of the Convention on International Trade in Endangered Species (CITES) biological criteria is concerned. In 1984, the IWC agreed on the basis of advice from its Scientific Committee, that the minke whale stock in the North-east Atlantic was depleted and should be protected under the rules then pertaining. Subsequently, some Norwegian scientists have disputed that advice, giving other 'explanations' for apparently declining catch rates over many years. But no one disputes that past Norwegian minke whaling, especially from 1930 through to 1984, had a substantial effect on the number of whales. There have been no recent calculations of the degree of depletion simply because the Revised Management Procedure (RMP) developed by the Scientific Committee and accepted in principle by the IWC, does not require such a calculation, with all its uncertainties.

Sharp's report seeks to reinforce the myth that the IWC takes no notice of its own scientific advisers. This too, is demonstrably untrue. What it has done is to say that scientific procedures alone cannot determine whether and in what circumstances the existing moratorium on commercial whaling can be modified. This depends equally on the existence of effective international control arrangements, both of whaling operations and of international trade in whale products. There is a consensus on that by all governments. And there are huge holes in present arrangements that must be plugged. 
Then, Sharp refers to a 'contention' that 'whales should be left to the IWC'. That too is a double distortion of the facts. First, the understanding is essentially that CITES should not act in contradiction of the IWC, considering that the IWC has both the scientific expertise and regulatory powers over whaling if not directly over trade. Second, this is not a 'contention' but a formal decision both by the Member States of the IWC and by the Parties to CITES, through a series of resolutions. In Nairobi, as well as in IWC meetings, Japan and Norway have tried to overturn all those decisions and failed.

Lastly, Sharp gives his personal version of the position on this matter taken by International Union for Conservation of Nature (IUCN) (which, incidentally, opposed all the downlisting proposals, as did the CITES Secretariat). It would have been better if he had quoted verbatim the IUCN position. But we leave that to the IUCN to correct.

\section{Sidney Holt}

International Ocean Institute

E-mail: sidneyholt@cs.com

Vassili Papastavrou

International Fund for Animal Welfare

E-mail:vassilip@compuserve.com

Cassandra Phillips

Worldwide Fund for Nature - International

Drs Holt and Papastavrou are regular participants in the IWC Scientific Committee.

\section{References}

Papastavrou, V. (1998) Sustainability: an elusive and misused concept. Oryx, 32, 86-87.

Sharp, R. (2000) CITES Conference of Parties 11: an FFI perspective. Oryx, 34, 228-230. 